\title{
The Role of HbA1c in Severity and Mortality Rate of ST Segment Elevation Myocardial Infarction for Hospitalized Libyan Non-Diabetic Patients
}

\author{
Asgad Abdalgbar ${ }^{1,2}$ and Hanan KG Altalhi ${ }^{1 *}$ \\ ${ }^{1}$ Faculty of Medicine, University of Omar El Mukhtar, Libya \\ ${ }^{2}$ Faculty of Medical Technology, University of Omar El Mukhtar, Libya
}

Submission: November 05, 2019; Published: December 03, 2019

*Corresponding author: Hanan KG Altalhi, Faculty of Medical Technology, University of Omar El Mukhtar, Albayda, Libya

\begin{abstract}
Background: The severity of coronary artery disease (CAD) is directly related to the quality of glucose control in diabetic patient. Additionally, diabetes is associated with increased mortality following acute myocardial infarction compared to general population.

Objectives: To evaluate the association of HbA1c level and severity of CAD, and outcome of non-diabetic patient with STEMI in our hospital.

Patients and Methods: 60 consecutives non-diabetic patient with acute ST elevation myocardial infarction were treated with thrombolytic therapy included in the present prospective study. Blood glucose and HbA1c level of all patients were measured within 3 hours of admission. Patient were divided in to 3 groups according to $\mathrm{HbA1c}$ level: with cut-off $6.5 \%$ as diagnostic criteria of diabetes mellitus according to (American diabetes association) group (1) 6.5\%, group (2) 6.5 to $8.5 \%$, group (3) $8.5 \%$ and above. In hospital. mortality and morbidities of acute STEMI were compared between groups.
\end{abstract}

Result: The mean age was $63 \pm 15$ year and mean body mass index was $26.6 \pm 6 \mathrm{~kg} / \mathrm{m}^{2}, 24$ patients $(40 \%)$ had history of hypertension, 27 patients (45\%) of dyslipidemia, 36 patients (60\%) were smoker. We found 45 patients with HbA1c $\leq 65 \%, 5$ patients with HbA1c $6.5-8.5 \%, 10$ patients with $\mathrm{HbA} 1 \mathrm{c} \geq 8.5 \%$. There was strong correlation between admission of HbA1c and admission glucose level $(\mathrm{P}<0.001)$. Infarct size as measured by peak creatinin kinase, was not correlated with HbA1c level.

Conclusion: HbA1c is an important risk marker in the absence of history of diabetes mellitus in patients with AMI. The optimal management in these patients may contribute in decrease hospital mortality.

Keywords: Glycosylated hemoglobin; ST elevation myocardial infarction; Mortalities; Diabetes; Glucose metabolism; Coronary syndrome; Catecholamine level; Cardiovascular disease; Hemoglobinopathies; Hypothyroidism; Tumor; Connective tissue

Abbreviations: SCAD: Coronary Artery Disease; HbA1c: Glycosylated Hemoglobin; STEMI: ST Elevation Myocardial Infarction; ECG: Electrocardiography

\section{Introduction}

Patients with diabetes are at 3-4 times increased risk for cardiovascular mortality compared with non-diabetes [1]. In acute coronary syndrome, glucose metabolism is modified and stress hyperglycemia commonly occur secondary to increase catecholamine level [2]. In addition to the higher rate of acute ST- elevation myocardial infarction (STEMI) in diabetes, hyperglycemia is associated with poor prognosis in these patients [3-5].

Higher HbA1c level was associated with high cardiovascular disease and death [6]. There were some other studies supporting the association between admission serum $\mathrm{HbA1c}$ level and increased long-term mortality of non-diabetic patients admitted with STEMI and higher rate CAD in these patients $[7,8]$. We have evaluated the association of admission level of $\mathrm{HbA1c}$ with the hospital outcome of non-diabetic patient with STEMI.

\section{Patients and Methods}

All patients of both sexes sustaining acute ST elevation myocardial infarction without diabetes were including in the study. Patients with sepsis, hemoglobinopathies or hypothyroidism, tumor, connective tissue diseases, those with sub-acute or chronic MI (longer than $48 \mathrm{hr}$ between first symptom and admission) those with renal failure, hepatic failure 


\section{Current Research in Diabetes \& Obesity Journal}

, iron deficiency anemia and those with past history of diabetes or used anti diabetic medication were excluded from the study.

Acute myocardial infarction was defined according to the (European Society of Cardiology and American College of Cardiology Criteria). Increased creatine kinase predominantly in the myocardial band fraction and or increased troponin I (creatine kinase $400 \mathrm{U} / \mathrm{L}$ or higher and or cardiac troponin I $2 \mu \mathrm{g} / \mathrm{L}$ or higher), ischemic symptoms (mainly constrictive chest pain, lasting longer than $30 \mathrm{~min}$ ), and or abnormal electrocardiography (ST elevation $1 \mathrm{~mm}$ or greater on at least two derivation). MI was defined as acute if the time elapsed between the first symptom and admission was $48 \mathrm{hr}$ or less. Only patients who underwent thrombolytic treatment were included in the study.

All patients were in cardiac care unit, a brief history was obtained from each patient presenting with acute chest pain including presence of risk factors like smoking and hypertension, dyslipidemia and previous history of ischemic heart disease. Clinical examination was done emphasis on signs of cardiac failure, 12 leads electrocardiography (ECG) was done at cardiac care unit and blood sample were sent to laboratory, blood glucose and HbA1c level of all patients were measured within $3 \mathrm{hr}$ of admission regardless of whether they had been fasting or not and for cardiac enzyme. The fasting lipid profile was determined on the morning following admission and included total cholesterol, high density lipoprotein and triglyceride.

All patients were considered for thrombolytic therapy (Injection streptokinase 1.5 million units over one hour) in the absence of all contraindication the management was according to standard treatment protocol. All patients underwent continues ECG monitoring for at least 48 hours on admission to cardiac care unit and daily during hospital stay.
Patients were divided into three groups according to the level of HbA1c with cut-off $6.5 \%$ as diagnostic criteria of diabetes mellitus according to (American Diabetes Association 2010) for diagnosis and classification of diabetes mellitus. Patient with HbA1c level of $4.5 \%$ to $6.4 \%$ group (1), patients with HbA1c level $6.5 \%$ to $8.5 \%$ group (2) and patients with $\mathrm{HbA1c}$ level higher than $8.5 \%$ group 3 ).

None of these patients received glucose, Insulin or potassium infusion therapy during admission. All subjects were hospitalized one week after acute myocardial infarction and hospital records were reviewed at this time.

Selective coronary angiography was performed after 1 month. Coronary angiogram were analyzed by two experienced observers who were blinded to the identities and clinical information of the patients. Vessel scores were ranged from zero to three, according to the number of diseased major pericardial vessel with significant stenosis (greater than $50 \%$ stenosis of the lumen diameter).

\section{Statistical analysis}

Was performed by using SPSS software (Version 12) difference among groups was analyzed by (t-test) and $\mathrm{P}$ value 0.05 was considerable significant.

\section{Result}

Table 1: Total 60 patients with STEMT were studied. Patients were divided on the bases of admission HbA1c group (1) $\leq 6.5 \%$; group (2) 6.5-8.5 \%; group $3 \geq 8.5 \%$. The clinical and biological characteristic according to $\mathrm{HbA1c}$ are summarized in Table 1. The mean age was $63 \pm 15$ year and mean body mass index was 26. $6 \pm 6 \mathrm{~kg} / \mathrm{m}^{2}, 24$ (40\%) had history of hypertension, 27 (45\%) of dyslipidemia, $36(60 \%)$ were smoker. We found 45 with HbA1c $\leq 6.5 \%$; 5 with HbA1c 6.5-8.5\%, 10 with HbA1c $\geq 8.5 \%$.

Table 1: Clinical and biological characteristics of the study subjects. according to admission HbA1c level.

\begin{tabular}{|c|c|c|c|c|c|}
\hline \multicolumn{6}{|c|}{ Level of Glycated Hemoglobin } \\
\hline & All $n=60$ & Group $1<6.5 \% n=45$ & Group 2 6.5-8.5\% N=5 & Group $3>8.5 \mathrm{~N}=10$ & P Value \\
\hline Age(year) & $63 \pm 15$ & $61 \pm 15$ & $60 \pm 17$ & $70 \pm 10$ & 0.02 \\
\hline $\operatorname{Sex}(M / F) n$ & $48 / 12$ & $40 / 5$ & $3 / 2$ & $7 / 3$ & 0.4 \\
\hline Current or former smoker (\%) & $36(60)$ & $29(65)$ & $2(40)$ & $6(60)$ & \\
\hline $\operatorname{BMI}\left(\mathrm{kg} / \mathrm{m}^{2}\right)$ & $26.6 \pm 6$ & $26.1 \pm 5$ & $26.7 \pm 4.2$ & $29 \pm 4.9$ & 0.05 \\
\hline Admission SBP (mmHg) & $132 \pm 25$ & $129 \pm 25$ & $136 \pm 22$ & $143 \pm 25$ & 0.05 \\
\hline Admission DBP (mmHg) & $72 \pm 18$ & $72 \pm 15$ & $71 \pm 14$ & $76 \pm 23$ & 0.05 \\
\hline $\begin{array}{l}\text { Admission plasma } \\
\text { glucose }(\mathrm{mmol} / \mathrm{L})\end{array}$ & $8.2 \pm 3.7$ & $7.7 \pm 2.9$ & $8.2 \pm 2.2$ & $11.2 \pm 6.5$ & $<0.0001$ \\
\hline Total cholesterol(mmol/L) & $6 \pm 1.2$ & $6.1 \pm 1.3$ & $6.3 \pm 0.9$ & $5.5 \pm 1.1$ & 0.01 \\
\hline HDL cholesterol (mmol/L) & $1 \pm 0.4$ & $1.3 \pm 0.4$ & $1.2 \pm 0.1$ & $1.2 \pm 0.3$ & 0.27 \\
\hline Triglyceride (mmol/L) & $1.53 \pm 0.89$ & $1.47 \pm 0.86$ & $1.88 \pm 0.89$ & $1.56 \pm 0.99$ & 0.36 \\
\hline Peak CK in first 24 hour (U/L & $903(210-3256)$ & $1979(580-3227)$ & $1500(647-3000)$ & $1486(504-3126)$ & NS \\
\hline
\end{tabular}




\section{Current Research in Diabetes \& Obesity Journal}

Data are mean \pm SD, BMI: Body Mass Index ie body weight $(\mathrm{kg})$ / hight ${ }^{2}\left(\mathrm{~m}^{2}\right)$. SBP/ DBP: Systolic / Diastolic Blood Pressure; CK: Creatinin kinase.

There was strong correlation between admission $\mathrm{HbA1} \mathrm{c}$ and admission glucose level $(\mathrm{P}<0.0001)$. Infarct size as measured by peak creatinine kinase, was not correlated with $\mathrm{HbA1c}$ level.
Table 2: Patients were divided according to admission glucose [group (1), $6.9 \mathrm{mmol} / \mathrm{L}$; group (2), 7 to $8.1 \mathrm{mmol} / \mathrm{L}$; group (3), 8.2 to $9.5 \mathrm{mmol} / \mathrm{L}$; group (4) $\geq 9.6 \mathrm{mmol} / \mathrm{L}$ ]. There was significant positive correlation between admission glucose and infarct size measured by peak creatinine kinase level $(\mathrm{P}<0.0001)$.

Table 2: Clinical outcome of non-diabetic patients based on quantities of admission plasma glucose.

\begin{tabular}{|c|c|c|c|c|c|}
\hline \multicolumn{7}{|c|}{ Admission Glucose Level } \\
\hline & IQR1 6.9 mmol/L & IQR2 7-8.1 mmol/L & IQR3 8.2-9.5mmol/L & IQR4 29.6mmol/L & P Value \\
\hline $\begin{array}{c}\text { Infarct size Peak.CK in } \\
\text { the first 24 hr }\end{array}$ & $530(210-1150)$ & $903(327-2050)$ & $1367(564-2924)$ & $1912(827-3256)$ & $<0.0001$ \\
\hline
\end{tabular}

IQR: Interquartile Range; CK: creatinine kinase. Value are expressed as median (IQR).

Table 3: At the end of fourth week coronary angiography performed in remaining 54 patients, revealed that there was significant correlation between $\mathrm{HbA1c}$ level at admission and number of disease vessel $(\mathrm{P}=0.001)$.

Table 3: Angiographic data of patients according to $\mathrm{HbA} 1 \mathrm{c}$.

\begin{tabular}{|c|c|c|c|c|}
\hline \multicolumn{5}{|c|}{ Level of Glycosylated Hemoglobin } \\
\hline Number of diseased vessel N (\%) & Group 1 <6.5\% N=39 & Group 2 6.5\%-8.5\% N=5 & Group 3 >8.58.5\% N=10 & P Value \\
\hline Single vessel & $30(76.9 \%)$ & $3(60 \%)$ & $1(10 \%)$ & 0 \\
\hline Double vessel & $7(17.9 \%)$ & $1(20 \%)$ & $4(40 \%)$ & 0.16 \\
\hline Triple vessel & $2(5.1 \%)$ & $1(20 \%)$ & $5(50 \%)$ & 0.001 \\
\hline
\end{tabular}

Table 4: We found that patients who died by day 5 were significantly different from patients with non-lethal acute myocardial infarction, with regard to admission plasma glucose $(16.6 \pm 5.4$ vs $8.3 \pm 3.4 \mathrm{mmol} / \mathrm{L}, \mathrm{P}=0.0001)$, age $(74 \pm 10$ vs $62 \pm 13$ year, $\mathrm{P}=0.002$ ).

Table 4: Clinical characteristics of patients according to the mortality at 5 days after acute myocardial infarction.

\begin{tabular}{|c|c|c|c|}
\hline & $\begin{array}{c}\text { Dead by day 5 } \\
\mathbf{N = 6}\end{array}$ & $\begin{array}{c}\text { Alive by day } \mathbf{5} \\
\mathbf{N = 5 4}\end{array}$ & P Value \\
\hline Age(year) & $74 \pm 10$ & $62 \pm 13$ & 0.002 \\
\hline Sex (M/F) & $6 / 0$ & $42 / 12$ & 0.33 \\
\hline $\begin{array}{c}\text { Peak creatinin } \\
\text { kinase (IU/L) }\end{array}$ & $\begin{array}{c}1068(1120- \\
3256)\end{array}$ & $\begin{array}{c}825(210- \\
1860)\end{array}$ & 0.02 \\
\hline $\begin{array}{c}\text { Admission } \\
\text { plasma glucose } \\
\text { (mmol/L) }\end{array}$ & $16.6 \pm 5.4$ & $8.3 \pm 3.4$ & 0.0001 \\
\hline HbA1c & $6.7 \pm 1.8$ & $6.2 \pm 0.2$ & 0.15 \\
\hline
\end{tabular}

HbA1c: Glycosylated Hemoglobin

There was no significant difference in $\mathrm{HbA1c}$ value in the survivor and non-survivor $(6.7 \pm 1.8$ vs $6 \pm 0.2, \mathrm{P}=0.15)$.

\section{Discussion}

The present study confirms previous observation in diabetic subjects suggesting that higher glucose level during AMI are associated with increased mortality [9]. In recent study, Timmer $\mathrm{J}$ et al, [7] reported that higher admission glucose level in non-diabetic patients treated with reperfusion therapy for ST segment elevation MI were associated with significantly larger enzymatic infarction size and lower left ventricular ejection fraction. This is because a stress response is accompanied by high level of catecholamine and cortisol and these hormones increase glucogenolysis and lipolysis and reduce insulin sensitivity, resulting in elevated glucose level [10]. There for, patients with elevated glucose level may represent with an increased stress response, due to more sever hemodynamic compromise or more extensive myocardial damage $[11,12]$.

Elevated cytokine, particularly tumor necrosis factor-Alpha (TNF- $\alpha$ ), also increase glucose level. TNF- $\alpha$ is released in AMI and directly decrease myocardial contractility, probably by inducing myocardial apoptosis [5,13]. TNF $-\alpha$ also cause impaired endothelial function [14]. This in turn, may be responsible for the impaired myocardial perfusion. We found positive correlation between peak creatinin kinase and admission plasma glucose concentration in our patients. Conversely, no correlation was found with HbA1c value. Although acute hyperglycemia at admission and during stay has clearly been associated with adverse outcome in patients with acute MI $[7,15,16]$.

Our study shows admission HbA1c level are not associated with high mortality in non-diabetic STEMI population treated with streptokinase. In our study high HbA1c in non-diabetic patients associated with multi vessels involvement of coronary arteries. Similarly, Cak Mak et al, [17] reported a significant correlation between $\mathrm{HbA} 1 \mathrm{c}$ level at admission and positive exercise that result after the four weeks follow up.

Hyperglycemia in STEMI patients was strongly associated with increased mortality within 5 days although there is clear 


\section{Current Research in Diabetes \& Obesity Journal}

correlation between admission glucose and HbA1c level, they appear to represent related but different phenomena. Patients with elevated glucose level have larger MI area.

Recently a prospective cohort study showed that in nondiabetic general population, as elevated HbA1c level is a risk factor for the development of cardiovascular events independently of fasting glucose [6]. The international expert committee recommended the use of HbA1c in diagnosis diabetes with a cut-off $6.5 \%$ [18].

The advantage of HbA1c over the fast blood glucose are its lower intra-individual variability, assessment in non-fasting state and superior in monitoring blood glucose level $[6,19]$. Preis \& Selvin et al, $[1,6]$ has suggested that glycosylated hemoglobin is superior to fasting blood glucose in predicting long-term risk of CAD in non-diabetes. Similar result is reported by Park and colleagues among non-diabetic women [20]. In a cohort of European men, khaw and colleagues [21] reported that HbA1c correlates linearly to subsequent cardiovascular morbidity [21]. The American Diabetes Association suggests that individual with HbA1c concentration of 5.7- 6.4\% should be informed of their increased risk for diabetes as well as cardiovascular disease [19, 22-27].

\section{Conclusion}

HbA1c is an important risk marker in the absence of history of diabetes mellitus in patients with AMI. The optimal management in these patients may contribute in decrease hospital mortality. People at high risk for type II diabetes mellitus should receive lifestyle counseling and if needed pharmacological therapy to reduce their risk of developing hyperglycemia and type II diabetes mellitus but specially to prevent or slow the development of CAD.

\section{References}

1. Preis S, Hwang S, Coady S, Pencina M, D Agostino R, et al. (2009) Trends in all-cause and cardiovascular disease mortality among women and men with and without diabetes mellitus in the Framingham Heart study, 1950 to 2005. Circulation 119(13): 1728-1735.

2. Husband DJ, Alberti KG, Julian DG (1983) Stress hyperglycemia during acute myocardial infarction: an indicator of pre-existing diabetes Lancet 2(8343): 179-181.

3. Wahab N, Cowden E, Pearce N, Gardner M, Merry H, et al. (2002) Is blood glucose an independent predictor of mortality in acute myocardial infarction in the thrombolytic era J Am Coll Cardiol 409(10): 1748-1754.

4. Wiviott S, Braunwald E, Angiolillo D, Meisel S, Dalby A, et al. (2008) Greater clinical benefit of more intensive oral antiplatelet therapy with prasugrel in patients with diabetes mellitus in the trial to assess improvement in therapeutic outcomes by optimizing platelet inhibition with prasugrel -Thrombolysis in myocardial infarction 38. Circulation 118(16): 1626-1636.

5. Li D, Zhao L, Liu M, Du X, Ding W, et al. (1999) Kinetics of tumor necrosis factor alpha in plasma and the cardioprotective effect of monoclonal antibody to tumor necrosis factor alpha in acute myocardial infarction. Am heart J 137(6): 1145-1152.
6. Selvin E, Streffes M, Zhu H, Matsushita K, Wagenknecht L, et al. (2010) Glycated hemoglobin, diabetes, and cardiovascular risk in non-diabetic adults. N Engl J Med 362(9): 800-811.

7. Timmer JR, Hoekstra M, Nijsten MW, Van Der Horest IC, Ottervanger JP, et al. (2011) Prognostic value of admission glycosylated hemoglobin and glucose in non-diabetic patients with ST-segmentelevation myocardial infarction treated with percutaneous coronary intervention. Circulation 124(6): 704-711.

8. Pai JK, Cahill LE, Hu FB, Rexorde KM, Manson JE, et al. (2013) hemoglobin $\mathrm{A} 1 \mathrm{c}$ is associated with increased risk of incident coronary heart disease among apparently healthy, non-diabetic men and women. J Am Heart Assoc 2(2): e000077.

9. Sewardsen M, Vythilingum S, Jailal I, Becker PJ (1989) Prognostic importance of admission plasma glucose in diabetic and non-diabetic patients with acute myocardial infarction. Q J Med 71(265): 461-466.

10. Seaquist ER, Anderson J, Childs B, Cryer P, Dagogo-Jack S, et al. (2013) Hyopglycemia and diabetes: a report of a workgroup of the American Diabetes Association and Endocrine Society. Diabetes Care 36(5): 1384-1395.

11. Gosselink AT, Liem AL, Reiffers S, Zijlstra F (1998) Prognostic value of predischarge radionuclide venrticulography at rest and exercise after acute myocardial infarction treated with thrombolytic therapy or primary coronary angioplasty. The Zwolle Myocardial Infarction Study Group. Clin Cardiol 21(4): 254-260.

12. DeGeare VS, Boura JA, Grines LL, O Neill WW, Grines CL (2001) Predective value of the Killip classification in patients undergoing primary precutaneous coronary intervension for acute myocardial infarction. Am J Cardiol 87(9): 1035-1038.

13. Li YP, Reid MB (2001) Effect of tumor necrosis factor-alpha on skeletal muscle metabolism . Curr Opin Rheumatol 13(6): 483-487.

14. Fujita H, Morita I, Murota S (1999) A possible involvement of in transporter in tumor necrosis factor alpha and cycloheximide-induced a apoptosis of endothelial cells. Mediators Inflamm 8(4-5): 211-218.

15. Capes S, Hunt D, Malmberg K, Gerstein HC (2000) Stress hyperglycemia and the risk of death after myocardial infarction in patients with and without diabetes : a systematic overview. Lancet 355(9206): 773-778.

16. Norhammar A, Tenerz A, Nilsson G, Efendic S, Ryden I, et al. (2002) Glucose metabolism in patients with myocardial infarction and no previous diagnosis of diabetes mellitus; a prospective study. Lancet 359(9324): 2140-2144.

17. Cakmak M, Cakmak N, Cetemen S, Tanrverdi H, Enc Y, et al. (2008) The value of admission glycosylated hemoglobin level in patients with acute myocardial infarction. Can J Cardiol 24(5): 375-378.

18. Melissa J Gillett (2009) International Expert Committee Report on the role of the A1C assay in the diagnosis of diabetes: Diabetes Care 2009; 32(7) 1327-1334. Clin Biochem Rev 30(4): 197-200.

19. American Diabetes Association (2010) Diagnosis and classification of diabetes mellitus. Diabetes care 33(4): 62-69.

20. Park S, Barrett-Connor E, Wingard DL, Shan J, Edelstein S (1996) GHB is better predictor of cardiovascular disease than fasting or post challenge plasma glucose in women without diabetes. The Rancho bernardo Study. Diabetes Care 19(5): 450-456.

21. Khaw K, Wareham N, Luben R, Bingham S, Oakes S, et al. (2001) Glycated haemoglobine, diabetes and mortality in men in Norfolk cohort of European prospective investigation of Cancer and Nutrition (EPIC-Norfolk) 322(7277): 15-18.

22. Ashra f H, Boroumand MA, Amirzadegan A, Talesh SA, Davoodi G (2013) Hemoglobin A1C in non diabetic patients: an independent predictor of coronary artery disease and its severity. Diabetes Res Clin Pract 102(3): 225-232. 


\section{Current Research in Diabetes \& Obesity Journal}

23. Diabetes Control and complication Trial (1996) The absence of glycemic threshold for the development of long-term complications: the perspective of the Diabetes Control and Complications trial Diabetes 45(10): 1289-1298.

24. Gerrity R, Natarajan R, Nadler J, Kimsey T (2001) Diabetes induced accelerated atherosclerosis in swine. Diabetes 50(7): 1654-1665.

25. Ghaffari S, Nadiri M, Pourafkari L, Sepehrvand N, Movasagpoor A, et al. (2014) The predictive value of total neutrophil count and neutrophil/ lymphocyte ratio in predicting in- hospital mortality and complications after STEMI. J Cardiovascular Thorac Res 6(1): 35-41.
26. Kassaian SE, Goodarznejad $H$, Boroumand MA, Salarifar M Masoudkabir F, et al. (2012) Glycosylated hemoglobin (HbA1c) level and clinical outcomes in diabetic patients following coronary artery stenting, Cardiovascular Diabetology 11: 82.

27. (2000) Myocardial infarction redefined-a consensus document of the Joint European Society of Cardiology/American college of cardiology Committee for the Redefinition of myocardial infarction. Eur Heart J 21(18): 1502-1513.

Your next submission with Juniper Publishers
will reach you the below assets
- Quality Editorial service
- Swift Peer Review
- Reprints availability
- E-prints Service
- Manuscript Podcast for convenient understanding
- Global attainment for your research
- Manuscript accessibility in different formats
- Undf, E-pub, Full Text, Audio)
Track the below URL for one-step submission
https://juniperpublishers.com/online-submission.php

